\title{
New species of the genus Inversidens Haas, 191 I (Unionoida, Unionidae, Gonideinae) from Jiangxi Province, China
}

\author{
Ruiwen Wu', Xiongjun Liu², Takaki Kondo ${ }^{3}$, Shan Ouyang ${ }^{4}$, Xiaoping $\mathrm{Wu}^{4}$ \\ I School of Life Science, Shanxi Normal University, Linfen 041000, China 2 School of Life Science, Jiaying \\ University, Meizhou 514015, China 3 Division of Natural Science, Osaka Kyoiku University, Osaka 582- \\ 8582, Japan 4 School of Life Sciences, Nanchang University, Nanchang 330031, China
}

Corresponding authors: Xiongjun Liu (609449126@qq.com); Xiaoping Wu (xpwu@ncu.edu.cn)

Academic editor: Graham Oliver | Received 24 May 2021 | Accepted 9 July 2021 | Published 3 August 2021

http://zoobank.org/BA743F4E-2452-432A-9796-E1DEBC1D4CAD

Citation: Wu R, Liu X, Kondo T, Ouyang S, Wu X (2021) New species of the genus Inversidens Haas, 1911 (Unionoida, Unionidae, Gonideinae) from Jiangxi Province, China. ZooKeys 1054: 85-93. https://doi.org/10.3897/ zookeys.1054.69075

\begin{abstract}
We diagnose and describe a new freshwater mussel species of the genus Inversidens, I. rentianensis sp. nov. from Jiangxi Province, China based on morphological characters and molecular data. This paper includes a morphological description and photograph of the holotype, and partial sequences of mitochondrial COI as DNA barcode data.
\end{abstract}

\section{Keywords}

COI, freshwater mussel, genetic distances, morphology, taxonomy

\section{Introduction}

The genus Inversidens Haas, 1911 belongs to the subfamily Gonideinae in the family Unionidae. The genus was first depicted by Haas (1911) as a subgenus of Nodularia with two species, i.e., Unio brandtii Kobelt, 1879 and Nodularia parcedentata Haas, 1911, both restricted to Japan. Later, Haas (1969) further classified Unio reinianus Kobelt, 1879, Unio haconensis Ihering, 1893, Unio japanensis Lea, 1859, Unio pantoensis Neumayr, 1899 within Inversidens. All species were restricted to Japan, except for 
U. pantoensis, which was distributed in China. By comparing the conchological characters, Kondo (1982) believed that $U$. brandtii was not morphologically distinct from $N$. parcedentata, and regarded $N$. parcedentata as a variety of $U$. brandtii. Based on the morphology of the glochidium, Habe (1991) removed U. reinianus from Inversidens, and established a new genus Inversiunio. Based on morphological characteristics of the shell, Kondo (1998) moved Unio haconensis, which was regarded as a synonym of Unio jokohamensis (Ihering, 1893), into Inversiunio. Furthermore, Starobogatov (1970) used Unio japanensis as the type species for his newly established genus Pronodularia.

Currently, only two species are recognized within Inversidens, the Japanese endemic I. brandtii and I. pantoensis in China (Fig. 1A, B; Kondo 2008; He and Zhuang 2013; Lopes-Lima et al. 2020; Graf and Cummings 2021a, b; MolluscaBase eds. 2021).

In this study, we diagnose and describe a new Inversidens species from Jiangxi Province, China. In addition, we provide estimations of the intraspecific and interspecific genetic distances within Inversidens based on the mitochondrial COI barcode to examine species validity.

\section{Materials and methods}

\section{Specimen collection and identification}

In March 2018, four samples were collected from the Mianshui River, Rentian Town, Ganzhou City, Jiangxi Province, China $\left(25.989557^{\circ} \mathrm{N}, 116.131333^{\circ} \mathrm{E}\right)$. All type and voucher specimens are deposited at the Biological Museum of Nanchang University, China (NCFM180325-NCFM180328).

\section{DNA extraction and $\mathrm{CO}$ amplification}

Of the four individuals, only two samples had tissues. Total genomic DNA was extracted from dissected somatic tissue using TIANamp Marine Animals DNA Kit (Tiangen Biotech, Beijing, China) according to the manufacturer's instructions.

Mitochondrial cytochrome oxidase subunit I (COI) gene sequences have been widely used for species delimitation of freshwater mussels based on genetic distance and the criteria of monophyly (Elderkin et al. 2016; Lopes-Lima et al. 2019; Smith et al. 2019). Polymerase chain reaction (PCR) amplification of the COI gene with a 680-base pair fragment was performed using a primer pair consisting of LCO1490 and $\mathrm{HCO} 2198$ (Folmer et al. 1994). Thermal cycling conditions were $98^{\circ} \mathrm{C}$ for $10 \mathrm{~s}$, followed by 35 cycles of $94^{\circ} \mathrm{C}$ for $1 \mathrm{~min}, 50^{\circ} \mathrm{C}$ for $1 \mathrm{~min}, 72^{\circ} \mathrm{C}$ for $1-2 \mathrm{~min}$, and a final extension of $72{ }^{\circ} \mathrm{C}$ for $7 \mathrm{~min}$, following the TaKaRa Ex manufacturer's protocol. The amplified PCR products were purified and sequenced by Sangon Biotech (Shanghai). The PCR product size for the COI amplicon was $680 \mathrm{bp}$. The sequences obtained in this study have been uploaded to GenBank. 


\section{DNA barcode dataset construction}

We constructed a mitochondrial COI dataset with the newly obtained sequences from this study and the available Inversidens brandtii sequences from GenBank.

Previously published sequences were downloaded from GenBank and added to the dataset, i.e., 17 species of the subfamily Gonideinae and four species of the subfamily Unioninae for the ingroup, and one species of the subfamily Parreysiinae as the outgroup.

As a result, a total of 29 COI sequences were used for this study. Sequence details and GenBank accession numbers are shown in Table 1.

All COI nucleotide sequences were translated to amino acid sequences using MEGA 5.0 (Tamura et al. 2011) and aligned based on the amino acid sequences using the program MUSCLE (Edgar 2004) with default settings. We calculated and compared inter-and intraspecific distances with MEGA 5.0 using the uncorrected $p$ distance. Standard error was assessed using 1000 bootstrap replicates.

Table I. List of sequences used in this study. $\left({ }^{*}\right)$ Sequenced from this study.

\begin{tabular}{|c|c|}
\hline Taxa & GenBank accession number \\
\hline \multicolumn{2}{|l|}{ UNIONIDAE Rafinesque, 1820} \\
\hline \multicolumn{2}{|l|}{ Parreysiinae Henderson, 1935} \\
\hline Indonaia andersoniana (Nevill, 1877) & KX865835 \\
\hline \multicolumn{2}{|l|}{ Unioninae Rafinesque, 1820} \\
\hline Acuticosta chinensis (Lea, 1868) & MG462919 \\
\hline Inversiunio jokohamensis (Ihering, 1893) & LC518985 \\
\hline Inversiunio reinianus (Kobelt, 1879) & LC518976 \\
\hline Nodularia douglasiae (Griffith \& Pidgeon, 1833) & NC_026111 \\
\hline \multicolumn{2}{|l|}{ Gonideinae Ortmann, 1916} \\
\hline Pseudodon bogani Bolotov, Kondakov \& Konopleva in Bolotov et al. 2017 & MF352216 \\
\hline Pseudodon manueli Konopleva, Kondakov \& Vikrev in Bolotov et al. 2017 & MF352228 \\
\hline Monodontina cambodjensis (Petit de la Saussaye, 1865) & KP795028 \\
\hline Pilsbryoconcha exilis (Lea, 1838) & KP795024 \\
\hline Chamberlainia hainesiana (Lea, 1856) & KX822635 \\
\hline Sinohyriopsis cumingii (Lea, 1852) & NC_011763 \\
\hline Sinohyriopsis schlegelii (Martens, 1861) & NC_015110 \\
\hline Lamprotula caveata (Heude, 1877) & KX822646 \\
\hline Lamprotula leaii (Griffith \& Pidgeon, 1833) & NC_023346 \\
\hline Potomida littoralis (Cuvier, 1798) & JN243905 \\
\hline Pronodularia japanensis (Lea, 1859) & KX822659 \\
\hline Gonidea angulata (Lea, 1838) & DQ272371 \\
\hline Leguminaia wheatleyi (Lea, 1862) & KX822651 \\
\hline Microcondylaea bonellii (Férussac, 1827) & KX822652 \\
\hline Sinosolenaia carinata (Heude, 1877) & KX822669 \\
\hline Ptychorhynchus pfisteri (Heude, 1874) & KY067440 \\
\hline Parvasolenaia rivularis (Heude, 1877) & KX966393 \\
\hline Inversidens brandtii (Kobelt, 1879) & AB040827 \\
\hline Inversidens brandtii (Kobelt, 1879) & MT020598 \\
\hline Inversidens brandtii (Kobelt, 1879) & MT020597 \\
\hline Inversidens brandtii (Kobelt, 1879) & LC519005 \\
\hline Inversidens brandtii (Kobelt, 1879) & LC519004 \\
\hline Inversidens rentianensis sp. nov. $1^{*}$ & MZ073336 \\
\hline Inversidens rentianensis sp. nov. $2^{*}$ & MZ073337 \\
\hline
\end{tabular}




\section{Phylogenetic analysis}

Bayesian inference (BI) analyses were inferred in MrBayes Version 2.01 (Ronquist et al. 2012), using GTRGAMMAI model of nucleotide substitution. Four chains were run simultaneously for 10 million generations and trees were sampled every 1000 generations. The first $25 \%$ of these trees were discarded as burn-in when computing the consensus tree (50\% Majority Rule). Sufficient mixing of the chains was considered to have been reached when the average standard deviation of split frequencies was below 0.01. Additionally, IQ-TREE was run for Maximum Likelihood (ML) tree reconstruction, using partition models with 1000 ultrafast bootstraps (Minh et al. 2013).

\section{Taxonomy}

Inversidens rentianensis $\mathrm{Wu} \& \mathrm{Wu}$, sp. nov. http://zoobank.org/62424717-9514-4C7D-9C0E-240F1D95F03E

Fig. 1C

Type specimens. Holotype. China • Jiangxi Province, Ganzhou City, Rentian Town (壬田镇), Mianshui River $\left(25.989557^{\circ} \mathrm{N}, 116.131333^{\circ} \mathrm{E}\right), 13$ March 2018, coll. Xiongjun Liu (NCFM180325). Paratypes. Same data as holotype (NCFM180326NCFM180328).

Diagnosis. Inversidens rentianensis sp. nov. is morphologically distinct from the other two recognized species within the genus by shell shape, beak position and nacre colour (Table 2). Diagnostic characteristics: shell irregularly subtriangular; curvature of the ventral margin slight, nearly straight; umbo situated $1 / 2$ of shell length; nacre reddish.

Description. Shell irregularly subtriangular, medium thickness, and quite inflated. Anterior margin regularly rounded; ventral margin nearly straight; posterior margin obliquely arc-shaped. Umbo prominent and slightly eroded. Umbo sculptured with feebly wavy wrinkles. Posterior slope formed by the ventral margin and posterior margin low, triangular. Epidermis shining black or with brownish-yellow hue. Only one cardinal tooth in each valve, shape triangular. Laterals thick, a little curved, 2 in each valve. Nacre reddish-bronze in colour.

Length 43-52 mm, height 29-36 mm.

Etymology. The specific epithet is derived from the type locality, Rentian Town.

Distribution. The species is known only from Mianshui River, Rentian Town, Ganzhou City, Jiangxi Province, China (present study) (Fig. 2).

GenBank accession number. Holotype, NCFM180325: MZ073336; paratypes, NCFM180326: MZ073337.

Molecular analyses. Pairwise COI sequence divergences from Inversidens brandtii and Inversidens rentianensis sp. nov. were conducted using MEGA 5.0. Based on the uncorrected $p$-distance model, the intraspecific divergences of $I$. brandtii and $I$. rentianensis sp. nov. were both $0.00 \%$. The interspecific divergence of $I$. 


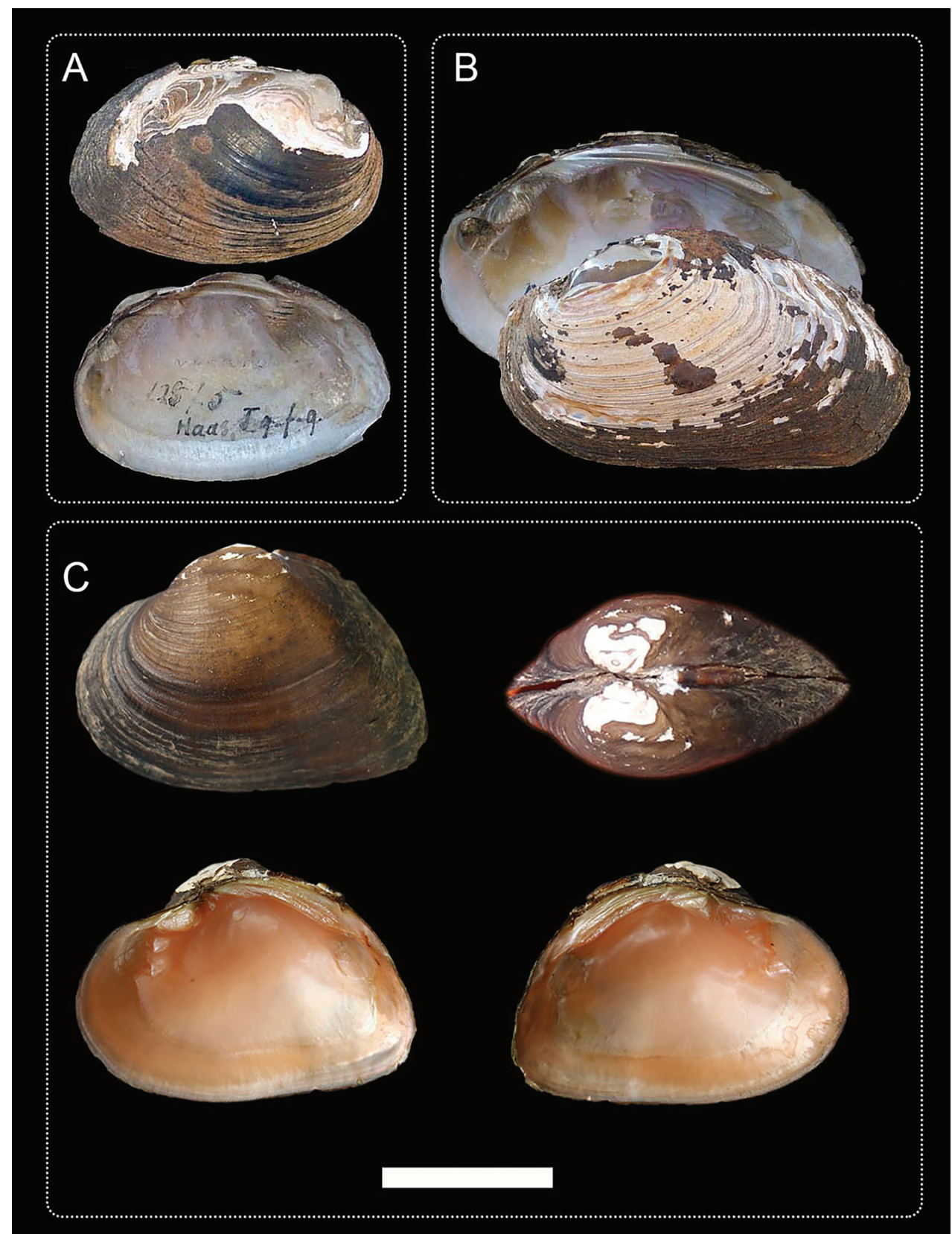

Figure I. Photographs of Inversidens taxa A I. brandtii B I. pantoensis C I. rentianensis sp. nov. Photos: [A, B] from the MUSSEL Project, [C] from this study, NCFM180325 (holotype), scale is $2 \mathrm{~cm}$.

brandtii and $I$. rentianensis sp. nov. was $10.1 \%$. Both BI and $\mathrm{ML}$ trees obtained a completely consistent topology. Consistent topology relationships are shown in Figure 3. In the phylogenetic trees, I. rentianensis sp. nov. formed a well-supported 
Table 2. Conchological characters of Inversidens rentianensis sp. nov., Inversidens brandtii, Inversidens pantoensis. Characteristic descriptions of I. brandtii and I. pantoensis are referenced from Kondo (1982, 2008) and He and Zhuang (2013).

\begin{tabular}{lccc}
\hline & I. rentianensis sp. nov. & I. brandtii & I. pantoensis \\
\hline Shell shape & Irregularly subtriangular & Ovate & Inequilateral, quadrate \\
Umbo position & $1 / 2$ of shell length & $1 / 4$ of shell length & $1 / 3$ of shell length \\
Umbo sculpture & Feebly wavy wrinkles & Rippled & Angularly wrinkled \\
Surface sculpture & Concentric ridges & Concentric ridges & Irregular growth lines \\
Nacre colour & Reddish & Milk-white & Bluish \\
Posterior slope & Sharp & Blunt & Blunt \\
Ventral margin & Nearly straight & Arc-shaped & Long and straight \\
\hline
\end{tabular}

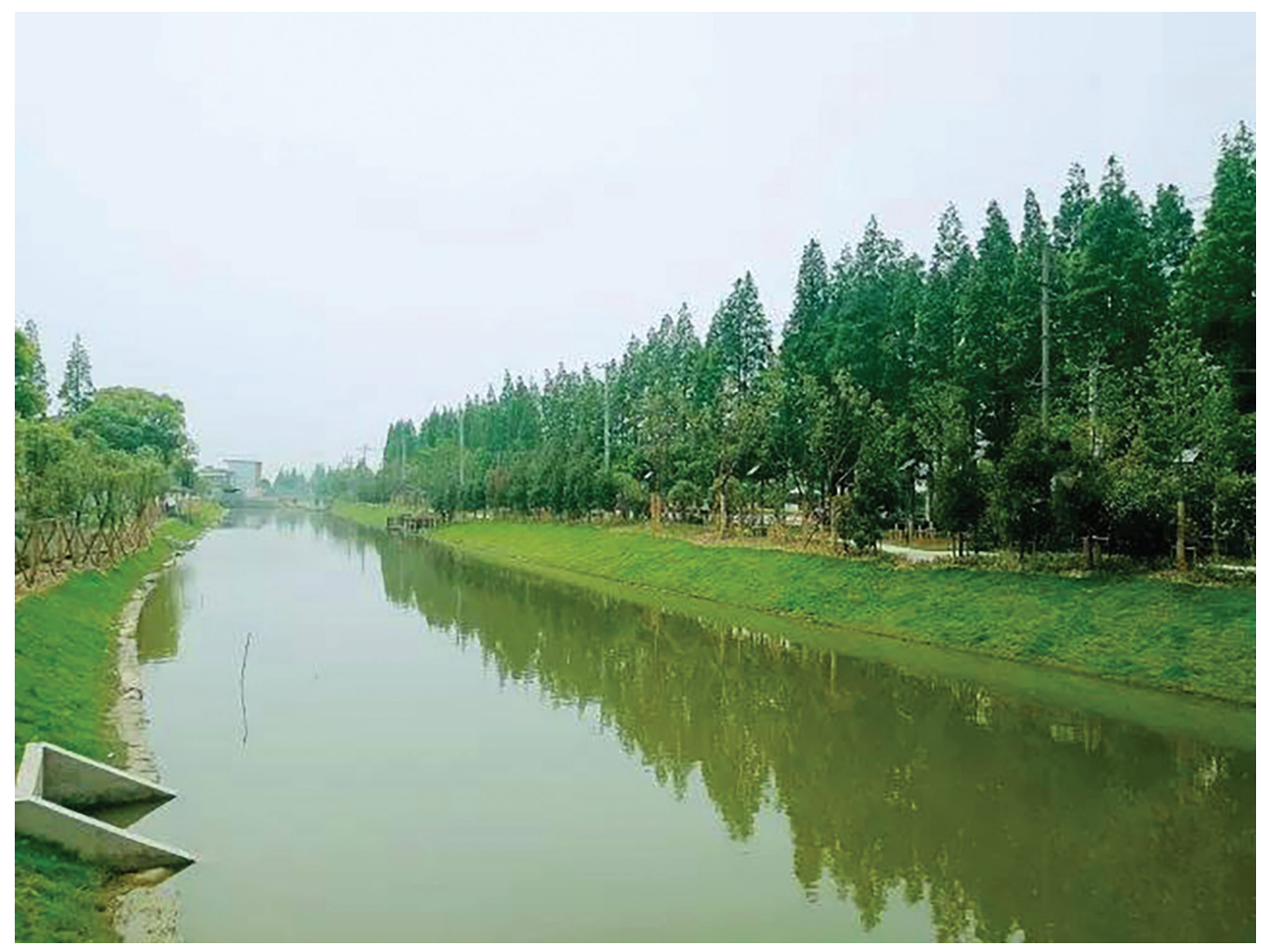

Figure 2. Photograph of sampling site of Inversidens rentianensis sp. nov. in China.

sister-group relationship with Inversidens brandtii $(\mathrm{PP}=1.00, \mathrm{BS}=100$; Fig. 3$)$. The genera Pronodularia and Inversiunio belong to different clades well-separated from Inversidens (Fig. 3).

Remarks. Species delineation can be problematic in the presence of morphological ambiguities due to phenotypic plasticity and convergence (e.g., cryptic species), especially in mollusks (Zieritz et al. 2010; Inoue et al. 2013). The use of molecular genetics can aid species delineation in the case of phenotypic plasticity and/or convergence (Pieri et al. 2018; Wu et al. 2018). Inversidens rentianensis sp. nov. can be 


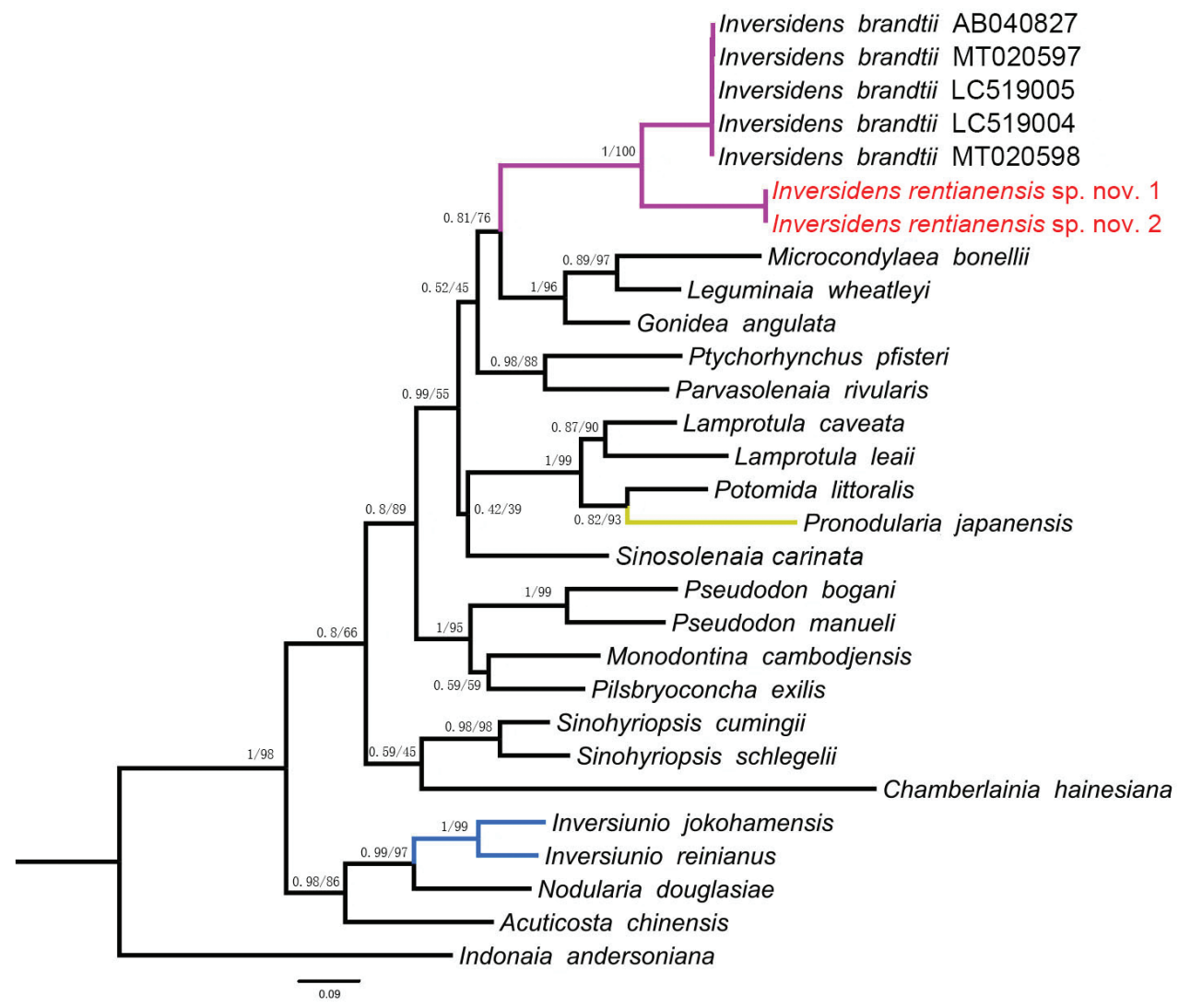

Figure 3. Phylogenetic tree of freshwater mussels inferred from Bayesian Inference (BI) and Maximum Likelihood (ML) analyses of COI barcode. Support values above the branches are posterior probabilities (PP)/bootstrap support (BS). Red font indicates the new species from this study.

distinguished from congeneric species based on diagnostic characteristics of the shell. In this study, we also analyzed the interspecific divergence between Inversidens brandtii and Inversidens rentianensis sp. nov. based on the COI barcode. The results showed that the average interspecific divergence between the two species was $10.1 \%$, which was much higher than intraspecific divergences. Genetic analysis conducted in this study supports I. rentianensis sp. nov. as a valid species, which can be easily distinguished by the COI barcode.

\section{Acknowledgments}

We thank the reviewer Dr Manuel Lopes-Lima, the other anonymous reviewer and the Subject Editor Dr Graham Oliver for valuable comments that have greatly improved this manuscript. This work was supported by the National Natural Science Foundation of China under Grant No.31772412. 


\section{References}

Doucet-Beaupré H, Blier PU, Chapman EG, Piontkivska H, Dufresne F, Sietman BE, Mulcrone RS, Hoeh WR (2012) Pyganodon (Bivalvia: Unionoida: Unionidae) phylogenetics: a male- and female-transmitted mitochondrial DNA perspective. Molecular Phylogenetics and Evolution 63: 430-444. https://doi.org/10.1016/j.ympev.2012.01.017

Edgar RC (2004) Muscle: multiple sequence alignment with high accuracy and high throughput. Nucleic Acids Research 32: 1792-1797. https://doi.org/10.1093/nar/gkh340

Elderkin CL, Clewing C, Wembo Ndeo O, Albrecht C (2016) Molecular phylogeny and DNA barcoding confirm cryptic species in the African freshwater oyster Etheria elliptica Lamarck, 1807 (Bivalvia: Etheriidae). Biological Journal of the Linnean Society 118(2): 369-381. https://doi.org/10.1111/bij.12734

Folmer O, Black M, Hoeh W, Lutz R, Vrijenhoek R (1994) DNA primers for amplification of mitochondrialcytochrome c oxidase subunit I from diverse metazoan invertebrates. Molecular Marine Biology \& Biotechnology 3: 294-299.

Graf DL, Cummings KS (2021a) A 'big data' approach to global freshwater mussel diversity (Bivalvia: Unionoida), with an updated checklist of genera and species. Journal of Molluscan Studies 87(1): 1-36. https://doi.org/10.1093/mollus/eyaa034

Graf DL, Cummings KS (2021b) The Freshwater Mussels (Unionoida) of the World (and other less consequential bivalves). MUSSEL Project Web Site. http://www.mussel-project.net/

Haas F (1969) Superfamilia Unionacea. Berlin: Walter de Gruyter.

Haas F (1911) Die Unioniden. [in] H.C. Küster, Systematisches Conchylien-Cabinet von Martini und Chemnitz 9 (pt. 2, h. 45): 89-112.

Haas F (1920) Die Neumayrschen Najaden aus der Ausbeute des Grafen Széchenyi. Senckenbergiana 2: 146-151.

Habe T (1991) Catalogue of non-marine molluscs in Japan. Hitachiobi 56: 3-7.

He J, Zhuang Z (2013) The Freshwater Bivalves of China. ConchBooks.

Inoue K, Harris JL, Robertson CR, Johnson NA, Randklev CR (2019) A comprehensive approach uncovers hidden diversity in freshwater mussels (Bivalvia: Unionidae) with the description of a novel species. Cladistics 36(1): 88-113. https://doi.org/10.1111/cla.12386

Inoue K, Hayes DM, Harris JL, Christian AD (2013) Phylogenetic and morphometric analyses reveal ecophenotypic plasticity in freshwater mussels Obovaria jacksoniana and Villosa arkansasensis (B ivalvia: Unionidae). Ecology and Evolution 3(8): 2670-2683. https://doi. org/10.1002/ece3.649

Jones JW, Neves RJ, Ahlstedt SA, Hallerman EM (2006) A holistic approach to taxonomic evaluation of two closely related endangered freshwater mussel species, the Oyster mussel Epioblasma capsaeformis and Tan Riffleshell Epioblasma florentina walker (Bivalvia: Unionidae). Journal of Molluscan Studies 72(3): 267-283. https://doi.org/10.1093/mollus/ eyl004

Kondo T (1982) Taxonomic revision of Inversidens (Bivalvia: Unionidae). Venus 41(3): 181-198. Kondo T (1998) Revision of the genus Inversiunio (Bivalvia: Unionidae). Venus 57(2): 85-93. Kondo T (2008) Monograph of Unionoida in Japan (Mollusca: Bivalvia). Special Publication of the Malacological Society of Japan (3): 32-34. 
Lopes-Lima M, Burlakova L, Karatayev A, Gomes-dos-Santos A, Zieritz A, Froufe E, Bogan AE (2019) Revisiting the North American freshwater mussel genus Quadrula sensu lato (Bivalvia Unionidae): Phylogeny, taxonomy and species delineation. Zoologica Scripta 48(3): 313-336. https://doi.org/10.1111/zsc.12344

Lopes-Lima M, Hattori A, Kondo T, Hee Lee J, Ki Kim S, Shirai A, Hayashi H, Usui T, Sakuma K, Toriya T, Sunamura Y, Ishikawa H, Hoshino N, Kusano Y, Kumaki H, Utsugi Y, Yabe S, Yoshinari Y, Hiruma H, Tanaka A, Sao K, Ueda T, Sano I, Miyazaki J-I, Gonçalves DV, Klishko OK, Konopleva ES, Vikhrev IV, Kondakov AV, Gofarov MY, Bolotov IN, Sayenko EM, Soroka M, Zieritz A, Bogan AE, Froufe E (2020) Freshwater mussels (Bivalvia: Unionidae) from the rising sun (Far East Asia): phylogeny, systematics, and distribution. Molecular Phylogenetics and Evolution 146: e106755. https://doi.org/10.1016/j. ympev.2020.106755

Minh BQ, Nguyen MAT, von Haeseler A (2013) Ultrafast approximation for phylogenetic bootstrap. Molecular biology and evolution 30(5): 1188-1195. https://doi.org/10.1093/ molbev/mst024

MolluscaBase eds (2021) MolluscaBase. http://www.molluscabase.org [on 2021-06-21.]

Pieri AM, Inoue K, Johnson NA, Smith CH, Harris JL, Robertson C, Randklev CR (2018) Molecular and morphometric analyses reveal cryptic diversity within freshwater mussels (Bivalvia: Unionidae) of the western Gulf coastal drainages of the USA. Biological Journal of the Linnean Society 124(2): 261-277. https://doi.org/10.1093/biolinnean/bly046

Ronquist F, Teslenko M, Mark PV, Ayres DL, Darling A, Höhna S, Larget B, Liu L, Marc A, Suchard MA, Huelsenbeck JP (2012) Mrbayes 3.2: Efficient Bayesian phylogenetic inference and model choice across a large model space. Systematic Biology 61: 539-542. https://doi.org/10.1093/molbev/mst024

Simpson CT (1914) A descriptive catalogue of the naiades, or pearly fresh-water mussels. Parts IIII. Bryant Walker, Detroit, Michigan. https://www.biodiversitylibrary.org/page/11344898

Smith CH, Johnson NA, Inoue K, Doyle RD, Randklev CR (2019) Integrative taxonomy reveals a new species of freshwater mussel, Potamilus streckersoni sp. nov. (Bivalvia: Unionidae): implications for conservation and management. Systematics and Biodiversity 17(4): 331-348. https://doi.org/10.1080/14772000.2019.1607615

Starobogatov Y (1970) Fauna of Molluscs and Zoogeographic Division of Continental Waterbodies of the Globe. Leningard Nauka.

Tamura K, Peterson D, Peterson N, Stecher G, Nei M, Kumar S (2011) Mega5: Molecular evolutionary genetics analysis using maximum likelihood, evolutionary distance, and maximum parsimony methods. Molecular Biology and Evolution 28: 2731-2739. https:// doi.org/10.1093/molbev/msr121

Wu RW, Liu YT, Wang S, Liu XJ, Zanatta DT, Roe KJ, Song XL, An CT, Wu XP (2018) Testing the utility of DNA barcodes and a preliminary phylogenetic framework for Chinese freshwater mussels (Bivalvia: Unionidae) from the middle and lower Yangtze River. PLoS ONE 13: e0200956. https://doi.org/10.1371/journal.pone.0200956

Zieritz A, Hoffman JI, Amos W, Aldridge DC (2010) Phenotypic plasticity and genetic isolation-by-distance in the freshwater mussel Unio pictorum (Mollusca: Unionoida). Evolutionary Ecology 24(4): 923-938. https://doi.org/10.1007/s10682-009-9350-0 